\title{
Tattua
}

JOURNAL OF PHILOSOPHY

\section{CHANGES OF THINKING MODE IN PEDAGOGICAL RESEARCH BASED ON PROCESS PHILOSOPHY}

\author{
Prof. Jing Zhang \\ Faculty of Educational Sciences \\ Capital Normal University, Beijing, China
}

\section{Introduction}

Recently, changes of thinking mode in pedagogical research are gaining momentum and increasing attention. Thinking mode is the deeper essence of man's cultural phenomena, the relatively stable and patternized thinking structure, habits, and set tendency utilized consciously or unconsciously by human beings to know the world, and highly integrated and generalized philosophic category. As a conception mode for human beings to construct the world, thinking mode is affected by social factors, such as production style, interaction style and living style. Moreover, in the field of academic study, especially in humanistic study, thinking mode frequently changes according to different basic approaches when man is pondering over philosophic problems. A pursuit of new thinking mode is actually a pursuit of new philosophy. Today, when we are submerged with various problems, the basic insights of 'process philosophy', which embody an essential meaning, can, to some extent, deal with many difficulties in this modern society. Therefore, people, who are paying attention to it, are unprecedentedly enthusiastic. This essay, based on the understandings of 
Whitehead's Process Philosophy, attempts to analyze the possibility in changes of thinking mode in pedagogical research of our country.

\section{Key Points of Process Philosophy}

Alfred North Whitehead, the well-known British philosopher, was a great master with wide-interest, keen-mind, and accomplished achievements in many academic fields. Tanaka, a Japanese expert studying Whitehead, named him "an ideologisi with seven faces." In 1929, he published his master piece Process and Reality, which systematically embodies elite thoughts of his whole life, and generated a gigantic (and organic) system of process philosophy. Process philosophy definitely and profoundly criticizes the dominant thinking mode and dual way of research in history of Western Philosophy. It is impossible to roundly summarize his process philosophy, neither is it the aim of this essay. The following is only a brief statement on the key ideas of process philosophy, with the hope of serving the purpose of subsequently analyzing what follows.

\section{a) Dismissing the 'entity' through "event theory" from the aspect of Ontology}

Ever since Aristotle, the ancient Greek philosopher, brought forward the concept of "entity", the abstract "entity" has been hanging over the subsequent Western philosophy of history, like a nightmare, and extendedly dominated human's thinking mode in aspect of Ontology. In modern times, Descartes developed this way of thinking. He presumed beforehand that entity exists independently by itself, and separately occupies its simple position in the time-space communities. There are two categories: substance entity and spirit entity. Substance entity took up a simple occupation in the extendedly spatial community, while spirit entity, developed by Humor, became "Images" occupying simple positions in time, which were independent from each other. Descartes' substance entity subsequently became the ultimate material in Natural Philosophy of Hobbes, the mechanical materialist, in which the whole world became a lifeless view with a group of substance entities functioning according to Newton's Three Laws. "The notion of 'entity' has been a significant footstone of Western philosophy ever since Socratic philosophy. Although Humor questioned it with his skeptical theory, 'entity' still influences thinking style of modern westerners, especially with the popularity of mechanic view on the world" (Zhihe Wang, 320). This way of thinking brought about many disadvantages, and also urged philosophers to deny concept of entity by different means. Due to the tradition of anti-entity, Whitehead even more thoroughly challenged the ghost of "Entity" from a completely different point of view. He incisively pointed out that 
Aristotle's dichotomy between entity and property originated in his simplified logic of dichotomy between "subject-predication". In The Concept of Nalure, Whitehead analyzed it in the following way:

A basic question Aristotle inquired was 'what does our so-called entity mean?' Unfortunately, his philosophy and his logic functioned here. In his logic, the basic category of positive proposition was a predication indicating the property of a subject. Therefore, in his analysis of many popular usages of the term 'entity', he emphasized its meaning as 'ultimate basis not judged by other analyses any more'. Hence entity was a ferm relative to 'predication'. Its characteristic was equivocal. But if we are going somewhere to look for 'entity', I will seek in events, which is the world's ultimate entity in a sense (Kuide Chen, 1988, 73).

In The Principle of Relativity and its Applicalion in Physics, Whitehead emphasized: "The ultimate facts in Nature are events; the essence of cognition by relativity is the ability of explicating events in virtue of time and space" (Kuide Chen, 1988, 53). The so-called event is a relation among the realistic fortunes interrelated in a fixed way. Whitehead regarded events as essential elements in the universe, which are in a floating state. That means when we are talking about all events in the nature, we are equivalently talking about the whole nature, for that apart from events, nothing is left, not even time and space, because they have already merged into "the flow of events". As to the characteristics of events, Whitehead pointed out that each event is a part of other events which includes itself; meanwhile each event includes other events as its parts. The main historical consequence of Whitehead's 'event theory' lies in that he advanced the core idea "events as ultimate element of the universe", and he abolished the concept "entity" by means of event theory. Although several years later Whitehead replaced the term "events" with "actual entity" and "actual occasion", some new realists after him incline remarkably to require "events" as the basic element of ontology, spurning the philosophic tradition of "objects" or "mind" as basic entities, and integrating the factor of time into philosophic ontology. That logically approaches the abolishment of the ancient concept "entity". This tendency influences, to some extent, main philosophic movements in the 20th century, which necessarily imposes important influence on thinking mode of educational and pedagogical research.

\section{b) Dispelling the opposition between subject and object through the concept of "prehension" from the aspect of Epistemology}

Process philosophy is also different from the traditional Western epistemology. The latter believes that distinguishing subject from object is the precondition for recognition 
to take place. Knower is outside and preexistent of recognized object, and only if so does knowing occur. Whitehead attempted to dispel the opposition befween subject and object through concept of "prehension". He believed that one octual entity is "prehended" or "felt" by another actual entity, and this is an absolute reciprocity. Experience is the precondition of substance's consciousness, not vice versa.

As for subject, contrary to traditional Western philosophic thoughts, there must be knower before carnying our actual recognition and obtaining knowledge. Whitehead argued that subject is the one executing the prehension function, and subject is the product of prehension activity. Feeler is the entia emerging from his own feeling activily. As a result, he proposed an important conception that self as the subject is a sudden emergence in the process.

As for object, Whitehead disagreed to the basic idea of traditional Western philosophy which looks at recognition of object as thing-in-itself out of recognition activity and the knower. He believed anything arousing specific activity on the subject is an object for recognition. In other words, object is also generated in recognition process. It interrelates with subject in the reality and it is the object of subject's recognition. Whitehead held that before recognition actually takes place, there is no so-called distinction between subject and object at all. Subject and object are gradually generated in the interactive process of "actual entity", and they ore interdependent and co-existent. The relation between subject and object as well as subject's recognition of object is also a gradual generation process. In this sense, Whitehead criticized the dualistic way of thinking on subject and object, which dominated the modern Western philosophy. He claimed that "all the modern philosophies are centered on how difficult to describe the world according to subject and predication, entity and property, special presentation and common presentation. The result is always against our direct experience". (Whitehead, 2003, 95) It is not hard to find out that Whitehead opposed any sense of dualism, especially Kant's dualism between phenomenon and reality. As to relationship between body and mind, Process Philosophy regards substance and spirit as well as body and mind as two elements of the same process, which are indivisibly related.

Compared to former philosophers and their philosophies, Whitehead distinguished his Process Philosophy as follows: Process philosophy discusses world's 'processness' and creativeness as its ontology, and holds the interactive generation and immanent unity between subject and object, knower and recognized object as its epistemology. This is different from all philosophers before him and their philosophies. Those schools of tradifional Western philosophy essentially watched, understood and interpreted the world and its essence from a static and planar viewpoint, and in a mode of subject-object dualism. On the contrany, Whitehead and his process 
philosophy watches, understands and interprets the world and its essence from a dynamic, interrelated and tridimensional viewpoint, in manner of immanent unity between subject and object. Consequently, it opposes all presetting, ensuring thoughts as well as dualism of subject and object; it emphasizes chanciness, processness, creativeness, generativeness, integrativeness and oneness, etc. These conceptions inspire consequently educational and pedagogical activities and thinking mode of research: we must exceed rigid conceptions, concern about events in education, pay attention to pedagogical process, emphasize chanciness and creativeness, oppose duality, stress interrelationship, and advocate multi-explanations of pedagogical phenomena.

\section{Principal characteristics of basic thinking mode in pedagogical research in China}

Pedagogical research in China has been heavily influenced by traditional thinking mode of Western philosophy of substance ever since beginning of the 20th century. The so-called substance thinking mode refers to the way of presetting Being as substance, understanding the universe as gather of substances, and interprefing everything with that premise. To put it in other words, it is a thinking style of "looking at everything from substance's viewpoint" (Meitang Sun, 2003, 9), which emphasizes drawing "universal" conclusions through abstract experiments or theoretical reasoning. The results are not necessarily true or rounded, neither can they effectively solve individualized problems in reality for sure, or definitely indicate the inevitable relation between pedagogical process and pedagogical effect, but the powerful inertia of this thinking mode used to attract numerous researchers to tirelessly and enthusiastically pursue universal conclusions in teaching and learning. The core of this mode is to understand Being as something existent, or to regard Being as a noun, as an absolutely still essence; the intricate world, preset in interactional movements, is seen as "the gather of entities", the substance world as actual world; it neglects the process of contradictive movements between substances, and therefore excluding the reality and objectivity of the relation world. Under the influence of this thinking mode, pedagogical research in our country exhibits the following characteristics:

\section{a) Way of interpreting Being relying on substance}

Substance thinking takes "ontology promise" as its precondition (Meitang Sun, 2003, 9): the infinitely complicated universe can be reverted into some basic substances, the absolute reality with set or immanent essence; the absolute reality exceeds geist and praxis, and it is the basis of the latter two. Substance thinking 
holds that the essence and property of things are indigenous to things themselves, are directly identical to things themselves. It's thinking logic is Being $=$ substance $=$ immanence. This immanence is solid and non-eliminable, or if put in another way, its elimination is the elimination of substance itself. Since substance and its immanence are directly identical, the essence of things is established, "inward", and preset. When there is something, there is its essence. Things and their essence are not generated, and they do not "become" themselves in the process. Under the influence of this interpretation, researchers on pedagogics hold the conviction that pedagogical phenomenon is objectively existent, that pedagogical laws are inward, unextinctive, and connatural by pedagogical activities themselves. Accordingly, the prime purpose of pedagogical research is to excavate the connatural essence infinitely and inwardly, to apply various research methods to "discover" or "reveal" the objective and universally effective "laws" and "essence" existing in pedagogical process. They believe that education itself embodies the so-called "essence" and "laws"; they try hard to seek objective knowledge and its ultimate basis and gist, or to seek the universally effective "absolute truth", because they mointain that truth is the copy or emersion of things' essence.

\section{b) Way of understanding the world as opposition between subject and object}

This thinking mode of research is non-reflective and non-critical thinking, which presets the separation befween subject and object, as well as subjectiveness and objectiveness; it presets a "thing itself" which is absolutely unrelated to reality and its practice. It insists that objective laws of education is independent from knower, that the researcher, research means and process are unrelated to the object of research, that subject and its practice do not compose the elements of objective things, contrarily, the premise of objective description is no other than excluding subjective factors. As a result, this thinking mode requires researchers as lookers-on or outliers, who imperturbably observe and analyze "pedagogical activities" as object of research, in order to reveal correctly the laws behind phenomenon. Consequently, the process of research on pedogogical activities not only doesn't pay attention to the researchers' subjective spirit bailment, but also restrains aspects of individual subjective world through various means. Therefore, theory and its basis (facts) become the focus of researchers, while subjective impressions, value judgments of realistic social bodies (including researchers and object of research) and all aspects of humanistic fields constituted by beliefs are regarded as elements harmful for researchers to obtain objective pedagogical "laws" and therefore are excluded and neglected. 


\section{c) "Being" and "What" as objects of thinking}

Substance thinking puts emphasis on analysis of "what", clarifying or finding out the signified corresponding to the signifier, instead of "to be" itself, nor generation, or "becoming". Being's being there, generotion of "to be", and the floating, changing process is replaced by "things" as a result of generation, which is Heidegger's so-called "pursuing existence but forgetting Being itself". This pursuit's typical exhibition in pedagogical research tends to pay attention to the actuality of research object through "simultaneous analysis", trying to obtain the universally effective knowledge according with deeper essence behind pedagogical phenomenon, or the universally applicable laws, through research procedures, such as abstraction and analysis in order to eliminate the false and refain the true. The background, cause and effect are not considered or not holistically undertaken in "diachronic analysis". It seems that universolly effective laws obtained from above-mentioned abstraction and analysis can complefely embody various "diachronic analysis" and their results.

Substance thinking once powerfully enhanced the development of human's knowledge and wisdom, and made important contribution to ologization of pedagogical activities. However, along with further expanding of human interaction, along with emergence of modern science, especially complex science, along with deeper philosophic problems, disadvantages of substance thinking have been gradually exposed to public. For example, because of the lack of subject, it fails to explain subject's position and action in emergence of Being, and it cannot indicate the pro-activity of subject and practice; as human's recognition is developing towards extreme fields, it is faced with more and more confirmative difficulty (e.g. on subatomic level, rigid and mechanic essence is eliminated; quanta's form depends on observation); consequently, substance thinking cannof effectively understand the complexity of subjectiveness and objectiveness, cannot satisfyingly solve the relation between thinking and being in order to realize the concrete and historical unification of subjectiveness and objectiveness, can not overcome the isolated, static and abstract speculation, and can not understand the living, floating and changing world.

\section{Changes of thinking mode in pedagogical research in China based on Process Philosophy}

Most traditional Western philosophers start their reasoning with substance thinking; therefore they inevitably look on the world by means of various static morphological analyzing approaches and thinking modes. But as Whitehead saw it, the world is 
a process. Everything in the event world is in a changing process, and integration and unification of various events compose organism; the basic characteristic of organism is action, and action is represented as a process; consequently, the whole world is exhibited as a process of activities. In brief, the world is a process, and the process is reality. The whole universe is a constantly creating and developing process, and the process character is their original and true station. Based on the ideas of Process Philosophy, thinking mode in pedagogical research should pay attention to the following aspects:

\section{a) Process thinking mode centered by generation}

Process Philosophy holds that "how 'actual entity' is generated composes what this actual substance is [...] its 'being' is composed by its 'generation" (Whitehead, 2003,40 ). That is, essence of things is "generated" in process of "to be", which is what is called being is prior to essence. Things exist in the process, and present as the process - in this sense, we may name it 'Process Thinking'. Each kind of things exists in the form of process, a process of constant transformation and generation among various stations. Characteristics of process present in individual thing, and individual thing also must be understood according to the process embodying the thing. Accordingly, when reflecting on pedagogical research, everything, including researcher's objects and research structure, is in a constant and endless movement. Therefore, when researchers in pedagogics objectively are facing pedagogical phenomenon, and changing pedagogical process and researchers themselves based on classroom pedagogical practice, it requires them to switch from entity thinking of asking "what" into process thinking of asking "how", to gradually and self-consciously cultivate attitude and thinking mode of emphasizing development and transition, to look on Being from viewpoint of "generation" and "process", and to replace substance thinking, with characteristics of being static, close and rigid, with process thinking, with characteristics of being dynamic, open and energetic. Only in this case the actual subject can, existing both as research subject and research object, indeed live up to not only look on object from aspect of "process", but also reflect on its self from aspect of generation. Certainly, this veer develops the useful and discards the useless rather than casting away completely, which regards "to be what" and "how to be" as a natural unification, and interpretively understands the meaning of "to be what" in process of "how generated".

\section{b) Interrelationship as viewpoint of understanding the world}

Process Philosophy believes that "actual entity" possesses character of universal relation: each entity is determined by other entities, and is exhibited as a being in 
relations. It is the result of multiple potential factors and their presentation; hence it is "generally relative". It is called process thinking to preset Being as dynamic relationship, to preset something existing as display of latent elements in relationship, and to interpref everything with it as premise. Therefore, each "actual entity" itself cannot be self-sufficiently "to be". It's "to be" relies on other substances, and is defined by the nature of relations in fields composed by numerous other substances. That is, existence of "actual entity" is not an isolated Being by itself; instead, it is formed by the combination and presentation of numerous potential factors by dint of specific medium and in specific time and space. Relation thinking is such kind of thinking that presetting Being as a dynamic relation, presetting the existent thing as explicit image of potential factors in relations, and interpreting everything with this premise (Meitang Sun, 2003, 9). Relation thinking is yet another important thinking mode that Process Philosophy provides to researchers. Relation thinking requires pedagogical research to dynamically, wholly and synthefically look on research object from a viewpoint of universal relation, from angle of inter-influence and interaction, rather than to obtain "simultaneous, objective laws" from isolated, still and unilateral recognition attitude. A case in point is the analysis and interpretation of the relation between teaching and learning, and between traditional pedagogy and modern pedagogy. This means that researchers must overcome fixed thinking mode of dualism, as what Whitehead did his utmost to oppose: the opposition between transferring knowledge and inspiring wisdom, the opposition between proposing freedom and obeying disciplines, and the opposition between science education and humanities education. From the viewpoint of regarding subject and object as immanent unity, researchers must not only regard the research object as universally related, inter-dependent, and interactively generated process, but also see our own subjective world as the same constant generation through universal related "process".

\section{c) "Being itself" and "to be" as thinking objects}

As Whitehead saw it, the realistic world is composed by constanlly changing "actual entities", therefore thinking objects should be focused on Being itself rather than something existing, on "to be" rather than "what". According to relation thinking, something existent is the end and image of Being, while Being acts as an embodiment of the floating and changing nature of the thing existing. Accordingly, a group of potential factors exist (to be) in a specific dynamic relation, and "what" it is will be naturally obvious enough. Wherefore when reflecting on pedagogy, it is believed that pedagogical activity is a process by nature, which is in an everlasting process of creation and transformation. Hence researchers on pedagogics need not only to understand actuality of research object, but also to further understand and master its cause and effect. Research on pedagogy should transform from focusing on 
"objective reality" in pedagogical activities to facing "events" and "actual entity" in pedagogy, from revealing "laws" to interpreting "Being". By sticking on selfconscious and reflective attitude, by clearly and properly "locating" the pedagogical research object from "process" angle, by utilizing "process" viewpoint embodying diachronic dimension and developing the useful and discarding the useless of simultaneous dimension, the basic thinking mode of pedagogical research will be realized.

\section{Conclusion}

Process Philosophy fries to break and overthrow philosophical theories and their traditions in Western history of philosophy, tries to solve metaphysical problems of Western philosophy from ancient time on, such as noumenon and phenomenon, single and multiple, dynamic and static, everlasting and changing, Being and generation, spirit and substance, determinism and free will. Process Philosophy becomes theoretical resources for following researchers to use for reference, because it canonizes process, emphasizes intra-relation, confirms the character of multisubjects, and appreciates creativity. Process Philosophy puts forword a new philosophic thinking mode, a new concept schema and interpretation manner in order to observe and understand the realistic world, and provides a new ideology, thoughts and viewpoints to enable us to actively reconstruct the harmonious relationship between wo/man and world, and among human beings, and to reconstruct a beautiful new world.

\section{Reference}

01. Chen, Kuide, Summary of Whitehead Philosophy Evolvement, Shanghai: Shanghai People's Press, 1988.

02. Sun, Meitang, From Substance Thinking to Practice Thinking And Interpretation of Being, Philosophical Trends, 2003.

03. Wang, Zhihe, Study on Posimodern Philosophical Thoughts, Beijing: Beijing University Press, 2006.

04. Whitehead, Allred North, Process and Reality, trans. Fubin Yang, Beijing: China City Press. 2003. 